\title{
УДК 338.431:631.155.6
}

\section{В. Ю. Епанчинцев}

ФГБОУ ВО «Омский государственный аграрный университет им. П.А. Столыпина», Омск, e-mail: vu.epanchintsev@omgau.org

\section{ИНФОРМАЦИОННО-КОНСУЛЬТАЦИОННОЕ СОПРОВОЖДЕНИЕ ФЕРМЕРОВ ПО ЗЕМЕЛЬНЫМ ВОПРОСАМ ПРИ ПОЛУЧЕНИИ ГОСУДАРСТВЕННОЙ ПОДДЕРЖКИ}

Ключевые слова: информационно-консультационная поддержка, земельные отношения, крестьянские фермерские хозяйства, агроконсалтинг, государственная поддержка.

С середины второго десятилетия двадцать первого века активизировалась поддержка со стороны государства малым формам хозяйствования в аграрной сфере экономики. В настоящее время привлечение денежных средств в форме гранта на финансирование большей части первоначальных расходов инвестиционного проекта принципиально возможно для абсолютного большинства фермеров Российской Федерации. Однако нередко барьером для получения бюджетных средств является низкий уровень подготовки данного проекта, в том числе по земельным вопросам, вследствие отсутствия качественного консалтингового сопровождения потенциального грантополучателя. В связи с этим, в статье проанализированы особенности информационно-консультационной поддержки в сфере аграрного землепользования при получении грантов, как начинающих фермеров, так и успешно развивающихся на протяжении нескольких лет фермерских хозяйств. Проведенное исследование раскрывает особенности взаимодействия субъектов консалтинговой инфраструктуры с малыми формам хозяйствования на различных этапах жизненного цикла аграрного бизнеса в процессе участия в конкурсном отборе получателей грантов «Агростартап», а также на развитие семейных ферм в отраслях животноводства и растениеводства. Работа имеет прикладной характер, основанный на практических ситуациях информационно-консультационного сопровождения фермеров в Омской области.

\section{Yu. Epanchintsev}

Omsk State Agrarian University named after P.A. Stolypin, Omsk, e-mail: vu.epanchintsev@omgau.org

\section{INFORMATION AND CONSULTING SUPPORT OF FARMERS ON LAND ISSUES TO OBTAIN STATE SUPPORT}

Keywords: information and consulting support, land relations, peasant farms, agricultural consulting, governmental support.

Since the middle of the second decade of the twenty-first century, government support for small forms of business in the agricultural sector of the economy has intensified. Attracting funds in the form of a grant to finance most of the initial costs of an investment project is fundamentally possible for the vast majority of farmers in the Russian Federation at the present time. However, often a barrier to receiving budget funds is the low level of preparation of this project, including on land issues, due to the lack of high-quality consulting support of a potential grantee. In this regard, the article analyzes the features of information and consulting support in the field of agricultural land use when receiving grants, both for novice farmers and for successfully developing farms for several years. The study reveals the peculiarities of the interaction of the subjects of the consulting infrastructure with small businesses at various stages of the life cycle of the agricultural business in the process of participating in the competitive selection of recipients of «Agrostartup» grants, as well as for the development of family farms, in the livestock and crop industries. The work is based on practical situations of information and consulting support of farmers in the Omsk region.

\section{Введение}

Земля в отличие от таких факторов производства, как труд, капитал, информация и предпринимательские способности, является основным ресурсом в сельском хозяйстве. В связи с его ограниченностью, особенно остро недостаток земель сельскохозяйственного назначения испытывают фермерские хозяйства, специализирующиеся на производстве как растениеводческой, так и животноводческой продукции. Очевидно, что для малых форм хозяйствования в агропромышленном комплексе (далее АПК) восполнение дефицита земли является наиболее сложной задачей. При этом в личных способностях по организации и развитию аграрного бизнеса фермеры не испытывают непреодолимых затруднений, доступность 
информации в эпоху глобальных цифровых решений также очевидна, основной рабочей силой, как правило, является непосредственно глава хозяйства и члены его семьи, а капитал возможно получить в форме государственной поддержки [1]. Однако разрешение земельной проблемы малого и среднего бизнеса в АПК включает не только финансовую составляющую, но и высококвалифицированное информационно-консультационное сопровождение, поскольку профессиональных компетенций необходимого уровня в сфере аграрного землепользования у сельских предпринимателей недостаточно.

Особенно остро потребность в качественном консалтинге по комплексу вопросов аграрного землепользования у фермеров появляется в процессе получения и прямой и косвенной государственной поддержки. В такой ситуации наиболее эффективным решением для малого агробизнеса является помощь консультантов. Актуальность исследования, в связи с этим, определена тем, что информационно-консультационное сопровождение фермерских хозяйств по земельным вопросам при получении софинансрования со стороны государства необходимо как для получения средств гранта, так и для успешной реализации инвестиционного проекта, на который грант получен.

Цель исследования состоит в анализе особенностей консалтингового сопровождения деятельности фермеров по земельным вопросам при получении финансовой и нефинансовой государственной поддержки в условиях активизации применения цифровых технологий в агропромышленном комплексе.

\section{Материал и методы исследования}

Результаты исследования основаны на следующих источниках информации:

- на материалах нормативно-правовых актов, регулирующих вопросы аграрного землепользования $[1,2,3]$;

- на материалах нормативно-правовых актов, регулирующих вопросы получения государственной поддержки малыми формами хозяйствования в АПК $[1,2,3]$;

- на материалах анализа организационно-технических аспектов информационноконсультационного сопровождения деятельности малых форм хозяйствования в АПК по земельным вопросам при получении прямой и косвенной государственной поддержки, проведенного автором.
Следует пояснить, что в статье не отражены субсидии фермерским хозяйствам, имеющие по экономическому содержанию компенсационный ретроспективный характер, поскольку они в основном покрывают уже произведенные затраты. С учетом того, что вопросы аграрного землепользования при оформлении субсидий имеют косвенный характер, в работе рассматривается государственная поддержка в форме грантов (прямая финансовая поддержка) и предоставления в аренду земельных участков без проведения торгов (косвенная нефинансовая поддержка).

При подготовке статьи были применены как общенаучные методы (в частности, анализ и синтез), так и общеэкономический метод сравнения. Предметом исследования являются организационно-экономические отношения между малыми формами хозяйствования в АПК (в данной работе: фермерскими и личными подсобными хозяйствами) и субъектами информационно-консультационного сопровождения АПК по вопросам аграрного землепользования, которые возникают в процессе получения прямой (в форме гранта) и косвенной (в форме права аренды земли без торгов) государственной поддержки.

Объектом исследования в статье являются особенности информационно-консультационной поддержки по земельным вопросам фермерских хозяйств при получении ими грантов, а также права долгосрочной аренды земли без участия в торгах.

Эмпирической базой для выполнения научной работы являются материалы консалтингового сопровождения деятельности малых форм хозяйствования АПК, полученные автором в процессе оказания Омским государственным аграрным университетом информационно-консультационной поддержки фермерским и личным подсобным хозяйствам Омской области в 2016 - 2020 годах.

\section{Результаты исследования и их обсуждение}

В условиях активной государственной политики по стимулированию создания и развития фермерских хозяйств, многие начинающие и действующие представители аграрного бизнеса подают пакет документов на получение поддержки со стороны государства. Она включает прямое финансирование по грантам:

- «Агростартап» (с 2019 года), софинансирование $90 \%$ стоимости первоначальных 
затрат инвестиционного проекта по созданию фермерского хозяйства;

- грант начинающим фермерам (до 2020 года включительно), софинансирование 90\% стоимости первоначальных затрат инвестиционного проекта по созданию фермерского хозяйства;

- грант на развитие семейной фермы, софинансирование 60\% стоимости первоначальных затрат инвестиционного проекта по развитию фермерского хозяйства.

В частности, в Омской области объем государственной поддержки, полученной крестьянскими фермерскими хозяйствами по вышеуказанным грантам в 2014 - 2020 годах, составил 1,69 миллиарда рублей, в том числе 665,38 миллиона рублей на создание малого аграрного бизнеса (табл. 1).

Также поддержка со стороны государства может быть предоставлена на развитие аграрного бизнеса в косвенной форме, которая заключается в получении фермерским хозяйством права на долгосрочную аренду земельного участка, необходимого для реализации масштабного (приоритетного) инвестиционного проекта без участия в торгах. Как правило, период такой аренды составляет 49 лет. Вследствие данной ситуации, у фермера возникает очевидное конкурентное преимущество в виде гарантированного земельного ресурса на определенном участке (участках) по тарифам арендной платы муниципалитета, которому принадлежит земля [4,5]. Воспользоваться такой поддержкой могут хозяйствующие субъекты, реализующие проекты в аграрной сфере на территории региона (в нашем случае,
Омской области) при соблюдении следующих условий:

- объем инвестиций должен быть не менее 50 (в некоторых случаях 100) миллионов рублей на территории муниципального района, в котором по проекту производится и перерабатывается сельскохозяйственная продукция;

- инвестиции (капитальные вложения) на момент подачи заявления в составе пакета документов, не осуществлены в полном объеме;

- фермерское хозяйство не имеет задолженности в бюджет и не состоит (не участвует) в процедуре банкротства;

- реализация проекта осуществляется на земельном участке, на котором не осуществляется иной инвестиционный проект.

В абсолютном большинстве случаев при подготовке пакета документов и дальнейшем получении всех рассмотренных выше форм государственной поддержки, у фермерских хозяйств возникает необходимость в информационно-консультационном сопровождении по вопросам аграрного землепользования (табл. 2).

Таблица 2 иллюстрирует многообразие аспектов аграрного землепользования по каждому из грантов (масштабные инвестиционные проекты рассмотрим ниже). В связи с этим, раскроем особенности информационно-консультационной поддержки по земельным вопросам крестьянских фермерских хозяйств при получении ими грантов. Автор обращает внимание, что грант начинающим фермерам не рассматривается, так как финансирование с 2021 года по нему не производится.

\section{Таблица 1}

Государственная поддержка, оказанная крестьянским фермерским хозяйствам Омской области в форме грантов в $2014-2020$ годах [3]

\begin{tabular}{|c|c|c|c|}
\hline $\begin{array}{c}\text { Период } \\
\text { получения } \\
\text { государственной } \\
\text { поддержки } \\
\end{array}$ & $\begin{array}{c}\text { Государственная } \\
\text { поддержка } \\
\text { начинающим } \\
\text { фермерам, млн руб. }\end{array}$ & $\begin{array}{c}\text { Государственная поддерж- } \\
\text { ка на развитие семейных } \\
\text { животноводческих ферм, } \\
\text { млн руб. } \\
\end{array}$ & $\begin{array}{c}\text { Гранты } \\
\text { «Агростартап», } \\
\text { млн руб. }\end{array}$ \\
\hline 2014 & 30,0 & 18,0 & \multirow{5}{*}{$\begin{array}{c}\text { Государственная } \\
\text { поддержка по гранту } \\
\text { «Агростартап» } \\
\text { осуществляется } \\
\text { с } 2019 \text { года }\end{array}$} \\
\hline 2015 & 46,2 & 42,9 & \\
\hline 2016 & 51,0 & 40,2 & \\
\hline 2017 & 94,2 & 74,0 & \\
\hline 2018 & 102,0 & 71,4 & \\
\hline 2019 & 102,0 & 72,9 & 71,1 \\
\hline 2020 & 118,28 & 84,174 & 50,6 \\
\hline Итого & 543,68 & 403,574 & 121,7 \\
\hline
\end{tabular}


Таблица 2

Информационно-консультационное сопровождение по вопросам аграрного землепользования при получении государственной поддержки фермерскими хозяйствами (составлено автором)

\begin{tabular}{|c|c|c|}
\hline $\begin{array}{l}\text { Вопросы аграрного землепользования, } \\
\text { возникающие при получении } \\
\text { государственной поддержки }\end{array}$ & $\begin{array}{c}\text { Периоды } \\
\text { жизненного цикла } \\
\text { фермерского } \\
\text { хозяйства } \\
\end{array}$ & \begin{tabular}{|c|} 
Субъекты \\
инфраструктуры \\
информационно- \\
консультационной \\
поддержки фермеров \\
\end{tabular} \\
\hline Получение земельных участков по гранту «Агростартап» & $\begin{array}{l}\text { Создание, } \\
\text { становление }\end{array}$ & Центры компетенций \\
\hline $\begin{array}{l}\text { Наличие земли в собственности или долгосрочной арен- } \\
\text { де для получения максимального количества баллов по } \\
\text { гранту «Агростартап» }\end{array}$ & $\begin{array}{l}\text { Создание, } \\
\text { становление }\end{array}$ & Центры компетенций \\
\hline $\begin{array}{l}\text { Наличие земли в собственности или долгосрочной арен- } \\
\text { де для получения максимального количества баллов по } \\
\text { гранту на развитие семейных ферм }\end{array}$ & Развитие & Центры компетенций \\
\hline $\begin{array}{l}\text { Определение площади земли, необходимой для реали- } \\
\text { зации проекта с привлечением средств государственной } \\
\text { поддержки (грант «Агростартап») }\end{array}$ & $\begin{array}{l}\text { Создание, } \\
\text { становление }\end{array}$ & $\begin{array}{l}\text { Образовательные и } \\
\text { научные учреждения, } \\
\text { центры компетенций }\end{array}$ \\
\hline $\begin{array}{l}\text { Определение площади земли, необходимой для реали- } \\
\text { зации проекта с привлечением средств государственной } \\
\text { поддержки (грант на развитие семейных ферм) }\end{array}$ & Развитие & $\begin{array}{l}\text { Образовательные и } \\
\text { научные учреждения, } \\
\text { центры компетенций } \\
\end{array}$ \\
\hline $\begin{array}{l}\text { Получение земельного участка в долгосрочную аренду } \\
\text { без торгов (масштабные инвестиционные проекты) }\end{array}$ & Развитие & $\begin{array}{l}\text { Образовательные и } \\
\text { научные учреждения }\end{array}$ \\
\hline
\end{tabular}

Таблица 3

Сравнительный расчет площади земли сельскохозяйственного назначения для балльной оценки производственных фондов при получении государственной поддержки в форме грантов начинающими фермерами

\begin{tabular}{|l|c|c|}
\hline \multicolumn{1}{|c|}{ Вид сельскохозяйственных животных } & Количество, голов & Площадь земли, га \\
\hline Быки-производители, коровы & 2 & 5 \\
\hline Молодняк (до 2 лет) & 3 & 4,5 \\
\hline Молодняк (до 2 лет) & 4 & 6 \\
\hline Мелкий рогатый скот & 20 & 5 \\
\hline Лошади, верблюды & 2 & 5 \\
\hline Птица всех видов & 100 & 5 \\
\hline Кролики, нутрии & 40 & 5 \\
\hline Пчелосемьи & 10 & 5 \\
\hline
\end{tabular}

Консалтинговое сопровождение по гранту «Агростартап» включает консультирование потенциальных получателей (в основном владельцев личных подсобных хозяйств) по подготовке к конкурсному отбору, проводимому региональным отраслевым органом исполнительной власти [6,7]. Необходимо определить максимально возможное количество баллов за наличие земельных участков в собственности или долгосрочной аренде (от трех лет), которые имеет возможность получить фермер. Также следует рассчитать площадь земли, необходимой для реализации проекта из расчета не менее
2,5 гектара на одну условную голову имеющегося поголовья сельскохозяйственных животных, указанного в пакете документов заявителя (табл. 3).

Консалтинговая поддержка по гранту на развитие семейных ферм также предполагает определение максимального количества баллов за наличие земельных участков в собственности или долгосрочной аренде (от пяти лет), которые может получить фермер. Аналогично предыдущему гранту рассчитывается площадь земли, необходимая для реализации инвестиционного проекта (табл. 3). 
Расчет необходимых посевных площадей для получения косвенной государственной поддержки на основании потребности в кормах

\begin{tabular}{|l|c|c|c|c|}
\hline Наименование & $\begin{array}{c}\text { Условное поголовье, } \\
\text { условных голов }\end{array}$ & $\begin{array}{c}\text { Потребность } \\
\text { в год, тонн }\end{array}$ & $\begin{array}{c}\text { Планируемая } \\
\text { урожайность, т/га }\end{array}$ & $\begin{array}{c}\text { Необходимые } \\
\text { посевные площади, га }\end{array}$ \\
\hline Силос (кукуруза) & 1744 & 15914,00 & 9,302 & 1710,81 \\
\hline Сено & 1744 & 1273,12 & 0,556 & 2289,78 \\
\hline Сенаж & 1744 & 11458,08 & 4,446 & 2577,17 \\
\hline Зернофураж & 1744 & 6365,60 & 1,706 & 3731,30 \\
\hline Солома & 1744 & 1273,12 & 0,585 & $\mathrm{X}$ \\
\hline Итого & 1744 & $\mathrm{X}$ & $\mathrm{X}$ & 10309,07 \\
\hline
\end{tabular}

Итак, информационно-консультационное сопровождение фермеров в части вопросов аграрного землепользования при получении грантов включает доказательную базу по имеющимся земельным участкам (сельскохозяйственного назначения), а также расчет площадей земли, необходимых для реализации инвестиционного проекта в различные периоды жизненного цикла фермерского хозяйства.

Консалтинговая поддержка по масштабным (приоритетным) инвестиционным проектам также имеет ряд особенностей, которые рассмотрены ниже.

1. Основной целью подготовки масштабного инвестиционного проекта является получение права долгосрочной аренды земельного участка (земельных участков) без торгов.

2. Как следствие, содержание такого проекта должно обосновывать необходимость использования площадей земельных участков (сельскохозяйственного назначения) в технологическом, биологическом и экономическом аспектах.

3. С учетом того, что реализация масштабного инвестиционного проекта может иметь ретроспективный характер, необходимо отразить наличие и использование в производственных целях земельных участков до момента подачи фермерским хозяйством пакета документов для получения косвенной государственной поддержки. Например, проект может быть включен в реестр масштабных (приоритетных) проектов с 2020 года, а его реализация фактически началась в 2015 году.

В качестве иллюстрации расчета необходимой площади земельных участков для реализации такого проекта в отрасли живот- новодства (с производственной точки зрения) представлена таблица 4.

Таким образом, информационно-консультационное сопровождение фермеров по земельным вопросам при получении государственной поддержки целесообразно рассматривать как сложную систему «информация - труд - земля», обладающую комплексом особенностей информационного, экономического и технологического характера, которые способствуют успешному созданию и развитию фермерских хозяйств. Консалтинг малых форм хозяйствования в сфере аграрного землепользования должен учитывать производственные, финансовые, правовые вопросы с целью повышения эффективности прямой и косвенной государственной поддержки малых форм хозяйствования в агропромышленном комплексе.

\section{Выводы}

Динамичное развитие технологий обуславливает не только экономическое содержание государственной поддержки фермерских хозяйств, но и изменение подходов к информационно-консультационному сопровождению ее получателей, в том числе по вопросам аграрного землепользования. С учетом объективной необходимости индивидуального подхода к клиенту, ключевой особенностью аграрного консалтинга по земельным вопросам является наличие высокого уровня профессиональных компетенций специалистов в области технологии производства продукции в конкретной отрасли сельского хозяйства, а также в области цифровых технологий. В свою очередь, деятельность информационно-консультативных систем с высоким уровнем качества 
в агропродовольственном комплексе приводит к повышению эффективности использования инноваций в сельскохозяйственном производстве (сорта, породы, техника, технология) на основании расчета земельной площади. Этим определяется значение ин- формационно-консультационной поддержки для рационального использования земель сельскохозяйственного назначения с учетом погодных и рыночных условий при необходимом уровне рентабельности сельскохозяйственного производства.

Исследование выполнено при финансовой поддержке Российского фонда фундаментальных исследований, проект 20-011-00088 «Архитектура земельных отношений и специфика землепользования в сибирских регионах: экономико-социологический подход».

\section{Библиографический список}

1. Сайт Министерства сельского хозяйства Российской Федерации [Официальный интернет-ресурс]. URL: https://mcx.gov.ru/analytics/ (дата обращения: 26.11.2021).

2. Постановление Правительства РФ от 14.07.2012 № 717 «О Государственной программе развития сельского хозяйства и регулирования рынков сельскохозяйственной продукции, сырья и продовольствия» (ред. от 14.05.2021) [Электронный ресурс]. URL: https://base.garant.ru/77306329/ (дата обращения: 25.11.2021).

3. Сайт Министерства сельского хозяйства и продовольствия Омской области [Официальный интернет-ресурc]. URL: http://msh.omskportal.ru/oiv/msh (дата обращения: 26.11.2021).

4. Долматова О.Н. Значение земельных ресурсов в системе современного рыночного сельскохозяйственного производства // Вестник Омского государственного аграрного университета. 2017. № 3 (27). C. 197-206.

5. Рогатнев Ю.М., Меданова К.В. Пути повышения доходности использования земель сельскохозяйственных организаций в условиях выраженной их разнокачественности // Землеустройство, кадастр и мониторинг земель. 2021. № 3. С. 172-179.

6. Демишкевич Г.М., Чепик Д.А. Роль института сельскохозяйственного консультирования в инновационном развитии аграрного сектора экономики России в условиях интеграции // Экономика сельского хозяйства России. 2018. № 12. С. 40-46.

7. Шмаков П.П., Савенко В.Г., Егоров Ю.Н., Можаев Е.Е. Инновационные направления в деятельности института сельскохозяйственного консультирования // Вестник Екатерининского института. 2020. № 4 (52). С. 64-69. 